\title{
Resource Use Efficiency on Different Farm Size Groups of Integrated Watershed Development Programmes Beneficiaries in Nagaland
}

\author{
S. Kanitoli Chishi and Amod Sharma* \\ Department of Agricultural Economics, Nagaland University SASRD, Medziphema Campus, \\ District: Dimapur - 797 106, Nagaland, India \\ *Corresponding author
}

\section{A B S T R A C T}

\section{Keywords}

IWDP, resource, farm, size, group, use-efficiency, beneficiaries

Article Info

Accepted:

17 May 2019

Available Online:

10 June 2019
The present study is to access the resource use-efficiency of watershed areas on the level of the beneficiaries and non-beneficiaries; for the purpose two districts from the Nagaland state viz., Dimapur and Zunheboto were selected purposely due to the maximum number of area covered under watershed in the zone; further two blocks from each district were randomly selected, which was finally having 8 numbers of watersheds areas is selected. In the second stage of sampling a multi stage random sampling was used for the selection of beneficiary and non-beneficiary viz., 160 respondents (80 beneficiaries and 80 nonbeneficiaries) were selected randomly from identified watershed areas. Study reveals that the. The value of co-efficient of multiple determinations $\left(\mathrm{R}^{2}\right)$ ranged from 98.75 per cent as maximum in large size group of farm to 79.84 per cent as minimum of the selected sample in overall farm size group, which will be explaining the variation in the dependent variables by the selected independent variable chosen in the equation in different farm size groups and in overall farms, which shows as good fit of the selected model. The remaining variation of dependent variable might be due to other variables, which have been used in excess or not properly used.

\section{Introduction}

Watershed Development Programmes have been accorded high priority in India's development plan. These programmes have been initiated in India to improve and sustain productivity and the production potential of the dry and semi-arid regions of the country through the adoption of appropriate production and conservation techniques (Anon. 2017; Chishi and Sharma, 2018). The WDP approach seeks to improve and develop all types of land viz., government forest, community land and private land; that fall within a particular watershed. It is a holistic approach to improve and develop the economic and natural resource base of dry and semi-arid regions (Dhakre and Sharma, 2010; Anon. 2016).

Effective use of land and water is fundamental to growth and sustainable development (Shuya and Sharma, 2014). The concept of watershed management has 
evolved to ensure effective use of both natural and social capitals. Thus, the watershed development programmes include land, water and human resources as essential components. The watershed programme is primarily a land based programme, which is increasingly being focussed on water, with its main objective being to enhance agricultural productivity through increased in situ moisture conservation and protective irrigation for socio-economic development of rural people (Walling et al., 2017; Shuya and Sharma, 2018).

Watershed is defined as a hydro-geological unit area from which the rainwater drains through a single outlet. Watershed development refers to the conservation, regeneration and judicious use of all the natural resources (like land, water, plants, animals) by human beings (Walling and Sharma, 2015). A watershed provides a natural geo-hydrological unit for planning any developmental initiative (Sharma, 2012b; Jamir and Sharma, 2018). The approach would be treatment from "ridge to valley". The present study having the two specific objectives viz., To evaluate the resource useefficiency of the sample farmers, and to study the marginal value product of Integrated Watershed Management Programme.

\section{Materials and Methods}

The present study is related to IWMP scheme, which is working as per the guideline of Central government with the help of Ministry of Agriculture, Government of India. Development projects require long period of time to reap benefits. Therefore for economic appraisal of development projects, it is essential that the project has been in operation for quite some time. Since the intensive IWMP started in 2008-09, so it is worth, while to study its impact. Since the data of the initial period cannot be compared with the data of recent years. It is more scientific and practical to compare the economy of the beneficiaries and non-beneficiaries covered in the area of IWMP schemes. The IWMP was launched in 2008-09 in all 11 district viz: Dimapur, Kohima, Kiphire, Longleng, Mokokchung, Mon, Phek, Peren, Tuensang, Wokha and Zunheboto of Nagaland (Anon., 2017), out of these districts two districts namely, Zunheboto and Dimapur districts of Nagaland selected because of the fact that it is expected to provide all the relevant information and hence can conveniently be obtained for conducting this study. The project area also has a good network of infrastructure and allied activities related to the scheme such as development agencies, well-established communication facilities. Keeping all the above facts, both districts of Nagaland were purposively selected to conduct this study. The primary data will be collected through pre-tested and prestructured schedules and questionnaires' especially designed for this study.

\section{Functional analysis}

In order to establish a functional relationship of different enterprises with its strategic input variables, Cobb-Douglas production function of the following type have been used to assess the impact of inputs towards the gross return; Similar studies were carried out by Sharma and Kalita (2008); Sharma (2014).

$\mathrm{y}=\mathrm{a} . \mathrm{x}_{1}, \mathrm{x}_{2}, \mathrm{x}_{3}, \mathrm{x}_{4}, \mathrm{x}_{5}, \mathrm{x}_{6}, \mathrm{x}_{7}, \mathrm{x}_{8} \ldots \mathrm{x}_{\mathrm{n}}$.

Whereas, a is constant,

$\mathrm{x}_{1}$ is Human labour cost in Rs / ha or animal,

$\mathrm{x}_{2}$ is Seed or sapling or animal or fingerling cost in Rs / ha or animal,

$\mathrm{x}_{3}$ is Fertilizer or nutrient cost in Rs / ha or animal, 
$\mathrm{X}_{4}$ is Plant protection or animal or fingerlings medicine cost in Rs / ha or animal,

$\mathrm{X}_{5}$ is Machinery or equipment used cost in Rs / ha or animal,

$\mathrm{x}_{6}$ is Transportation cost in Rs / ha or animal,

$\mathrm{x}_{7}$ is Marketing cost in Rs / ha or animal,

$\mathrm{X}_{8}$ is Miscellaneous cost in Rs / ha or animal and

$\mathrm{y}$ is the total cost in Rs / ha or animal.

The function becomes linear in logarithmic form as

$\log y=\log a+b_{1} \log x_{1}+b_{2} \log x_{2}+b_{3} \log$ $\mathrm{x}_{3}+\mathrm{b}_{4} \log \mathrm{x}_{4}+\mathrm{b}_{5} \log \mathrm{x}_{5}+\mathrm{b}_{6} \log \mathrm{x}_{6}+\mathrm{b}_{7} \log$ $\mathrm{x}_{7}+\mathrm{b}_{8} \log \mathrm{x}_{8}+\ldots \ldots . \mathrm{b}_{\mathrm{n}} \log \mathrm{x}_{\mathrm{n}}$

The Cobb-Douglas production function allows greater degree of freedom and has the advantage over other types of function as the estimated can be computed conveniently.

The regression co-efficient $\left(b_{1}\right)$ in CobbDouglas production function directly indicate the elasticity of production which measures the percentage change in out for unit percentage change in the input (Sharma, 2012a).

The Cobb-Douglas production function facilitates to examine the resource use efficiency by comparing marginal value product (MVP) to its factor cost.

The marginal value product of an input is computed as follows: $M V P x_{1}=d_{y} / d_{x}=b_{1}$ y $/ \mathrm{x}_{1}$,

Where $b_{1}$ is the elasticity co-efficient of $x_{1}, x_{1}$ and $y$ are the geometric means of input and output respectively.

\section{Results and Discussion}

Cobb-Douglas Production Functions have been used in the present study for the assessment of the resource use efficiency of different enterprises viz., crop production, livestock and plantation crops on different farm size groups in the selected area. The production function of different enterprises were fitted as regressing gross return $(\mathrm{y}), \mathrm{x}_{1}$, $\mathrm{x}_{2}, \mathrm{x}_{3}, \mathrm{x}_{4}, \mathrm{x}_{5}, \mathrm{x}_{6}, \mathrm{x}_{7}$ and $\mathrm{x}_{8}$ in terms of rupees as independent variables on marginal, small and medium farm size groups as well as overall farm size group.

Table 1 reveals the ordinary least square (OLS) estimates of parameters of CobbDouglas type of production with respect to different farm size groups. The regression coefficient of input a was found to be positive with significant at 1 per cent level, which indicate that model is good fit, while the negative values has no role or very little role towards the gross return, besides the contribution of the constant is having the importance if all the selected inputs variables were kept as constant. Similar studies were carried out by Sharma et al., (2007); Sharma (2013).

In case of $\mathrm{x}_{2}$ it was found to be positive in overall (4826.14) with maximum return and medium (406.68) with minimum return, as both the variables were found to be statistically significant at 1 per cent level, which indicates a good fit with more potential in compare to other inputs toward the gross returns. While in small and large farm size groups it was found to be statistically nonsignificant, which revealed that inputs having less contribution towards the gross return.

The regression co-efficient of $\mathrm{x}_{3}$ was found to be (209.85) with statistically significant at 10 per cent level in medium farm size group, which shows that in compare to the other 
farm size groups it could be better utilized on the farm, because of having positive role for gaining the more net return. While on other farms its contribution is less or may be utilized or used in excess, which ultimate provides the negative response towards the gross return. So it may be concluded that the investment on the medium farm size group may have further more potential after the investment or by shifting the other inputs for getting better return.

The value of $\mathrm{x}_{4}$ ranges from 487.02 to 427.19 in medium and large size farm group, as both were found to be statistically significant at 10 per cent and 1 per cent level, respectively, which shows the positive significant contribution of the inputs to the gross return. So it will be better to shift the other inputs as an investment to these inputs for getting better prospects as well as benefiting the farmers, which indicates that in the coming days it is better to shift the inputs to the potential areas to get maximum profit after reshuffling them, in compare to other inputs, it has little contribution towards the gross return.

The value of $\mathrm{x}_{5}$ (971.75) in small size farm group was found to be statistically significant at 1 per cent level, which shows the positive significant contribution of the inputs to the gross return. So it will be better to continue the investment on the input for getting better prospect as well as benefiting the farmers too which indicates that in the coming days it is better to shift the inputs to the potential area to get maximum profit in compare to other inputs, wherever having more potentiality towards the gross return.

The value of $\mathrm{x}_{6}(127.113)$ in small size farm group was found to be statistically significant at 10 per cent level, which shows the positive significant contribution of the input to the gross returns. So it will be better to continue the investment on the input for getting better prospect, which indicates that in the coming days it is better to shift the inputs to the potential area to get maximum profit in compare to other inputs, however getting positive response and having more potentiality towards the gross return.

The value of $\mathrm{x}_{7}$ ranging from (13761.26) as maximum value to (6167.91) as minimum value in medium to large size farm groups, respectively were found to be statistically significant at 1 per cent level, which shows the positive significant contribution of the inputs to the gross return. So it will be better to continue the investment on these inputs for getting better prospects as well as benefiting the farmers after reshuffling the input cost, which indicates that in the coming days it is better to invest more to these inputs due to the potentiality variables and to get maximum profit in compare to other inputs. The value of $\mathrm{x}_{8}$ ranging from (13761.26) as maximum value to (6167.91) as minimum value in medium to large size farm groups, respectively were found to be statistically significant at 1 per cent level, which shows the positive significant contribution of the inputs to the gross return. So it will be better to continue the investment on these inputs for getting better prospects as well as benefiting the farmers after reshuffling the input cost, which indicates that in the coming days it is better to invest more to these inputs due to the potentiality variables and to get maximum profit in compare to other inputs.

By aggregating the cross-sectional data of all the farms in various farm size groups, production has been estimated for all the selected sample farms. The ordinary least square (OLS) estimates of parameters have been showed in table 1 . The value of $R^{2}$ in all farm samples were found to be 0.76 , which shows that 76 per cent of the variation of dependent variable explained by the independent variation chosen in the equation. 
Table.1 Elasticity co-efficient of different enterprises on beneficiaries farm size groups

\begin{tabular}{|c|c|c|c|c|c|}
\hline $\mathbf{S N}$ & No's of Obs. & Variables & Reg. Co-effi. & t-Statistics & $\mathbf{R}^{2}$ \\
\hline (i). & \multicolumn{5}{|c|}{ Marginal farm size group } \\
\hline 1. & \multirow{9}{*}{10} & $\mathrm{a}$ & $\begin{array}{l}-16384^{\mathrm{NS}} \\
(5.09 \mathrm{E}+10)\end{array}$ & $-3.2 \mathrm{E}-07^{\mathrm{NS}}$ & \multirow{9}{*}{$\begin{array}{c}0.995627^{* * *} \\
(312.048)\end{array}$} \\
\hline 2. & & $\mathrm{x}_{1}$ & $\begin{array}{l}0.025571^{\mathrm{NS}} \\
(0.038727)\end{array}$ & $0.660283^{\mathrm{NS}}$ & \\
\hline 3. & & $\mathrm{x}_{2}$ & $\begin{array}{l}33.91158^{*} \\
(24.25238)\end{array}$ & $1.398279^{*}$ & \\
\hline 4. & & $\mathrm{x}_{3}$ & $\begin{array}{l}-15.3005^{\mathrm{NS}} \\
(8.979653)\end{array}$ & $-1.70391^{\mathrm{NS}}$ & \\
\hline 5. & & $\mathrm{x}_{4}$ & $\begin{array}{l}3.17 \mathrm{E}+16^{\mathrm{NS}} \\
(2.96 \mathrm{E}+16)\end{array}$ & $1.072674^{\mathrm{NS}}$ & \\
\hline 6. & & $x_{5}$ & $\begin{array}{l}-42.0953^{\mathrm{NS}} \\
(27.14217)\end{array}$ & $-1.55092^{\mathrm{NS}}$ & \\
\hline 7. & & $\mathrm{x}_{6}$ & $\begin{array}{l}44.36427^{* * * *} \\
(30.91366)\end{array}$ & $1.435103^{* * * *}$ & \\
\hline 8. & & $\mathrm{x}_{7}$ & $\begin{array}{c}244.4481^{* * *} \\
(131.2289)\end{array}$ & $1.862762^{* * * *}$ & \\
\hline 9. & & $\mathrm{x}_{8}$ & $\begin{array}{l}-5 \mathrm{E}+15^{\mathrm{NS}} \\
(4.62 \mathrm{E}+15)\end{array}$ & $-1.07267^{\mathrm{NS}}$ & \\
\hline (ii). & \multicolumn{5}{|c|}{ Small farm size group } \\
\hline 1. & \multirow{9}{*}{ 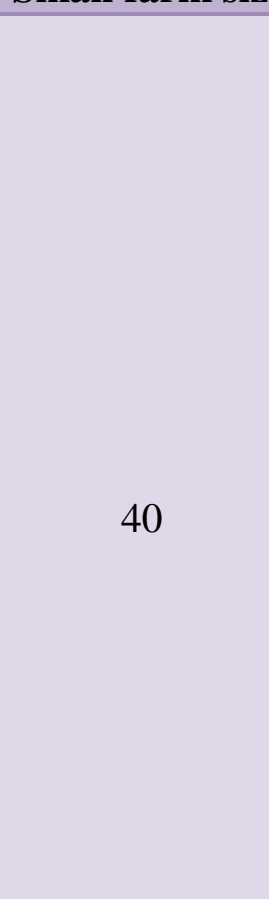 } & a & $\begin{array}{c}2723.806^{* * * *} \\
(3.912539)\end{array}$ & $1.886113^{* * * *}$ & \multirow[t]{9}{*}{$\begin{array}{l}0.870789^{* * *} \\
(1527.016)\end{array}$} \\
\hline 2. & & $\mathrm{x}_{1}$ & $\begin{array}{c}0.19939^{*} \\
(0.088797)\end{array}$ & $2.245466^{*}$ & \\
\hline 3. & & $\mathrm{x}_{2}$ & $\begin{array}{l}4.847295^{*} \\
(3.912539)\end{array}$ & $1.238913^{*}$ & \\
\hline 4. & & $\mathrm{x}_{3}$ & $\begin{array}{l}-4.87357^{\mathrm{NS}} \\
(4.984829)\end{array}$ & $-0.97768^{\mathrm{NS}}$ & \\
\hline 5. & & $\mathrm{x}_{4}$ & $\begin{array}{l}53.15255^{*} \\
(259.3595)\end{array}$ & $0.204938^{*}$ & \\
\hline 6. & & $x_{5}$ & $\begin{array}{l}-11.1585^{\mathrm{NS}} \\
(67.17767)\end{array}$ & $-0.1661^{\mathrm{NS}}$ & \\
\hline 7. & & $\mathrm{x}_{6}$ & $\begin{array}{c}-1.0825^{\mathrm{NS}} \\
(1.791139)\end{array}$ & $-0.60436^{\mathrm{NS}}$ & \\
\hline 8. & & $x_{7}$ & $\begin{array}{c}6.654108^{*} \\
(17.58313)\end{array}$ & $0.378437^{*}$ & \\
\hline 9. & & $\mathrm{x}_{8}$ & $\begin{array}{l}-0.20627^{\mathrm{NS}} \\
(2.452675)\end{array}$ & $-0.0841^{\mathrm{NS}}$ & \\
\hline
\end{tabular}




\begin{tabular}{|c|c|c|c|c|c|}
\hline (iii) & Medium & rou & & & \\
\hline 1. & \multirow{9}{*}{10} & $\mathrm{a}$ & $\begin{array}{l}-5750.69^{\mathrm{NS}} \\
(5319.275)\end{array}$ & $-1.0811^{\mathrm{NS}}$ & \multirow{9}{*}{$\begin{array}{l}0.99505^{\text {**** }} \\
849.6419)\end{array}$} \\
\hline 2. & & $\mathrm{x}_{1}$ & $\begin{array}{c}0.095459^{\mathrm{NS}} \\
(0.204114)\end{array}$ & $0.467673^{\mathrm{NS}}$ & \\
\hline 3. & & $\mathrm{x}_{2}$ & $\begin{array}{l}7.061947^{*} \\
(6.164715)\end{array}$ & $1.145543^{*}$ & \\
\hline 4. & & $\mathrm{x}_{3}$ & $\begin{array}{l}25.75573^{* * * *} \\
(15.20491)\end{array}$ & $1.693909^{* * *}$ & \\
\hline 5. & & $\mathrm{x}_{4}$ & $\begin{array}{l}-103.514^{\mathrm{NS}} \\
(92.39518)\end{array}$ & $-1.12034^{\mathrm{NS}}$ & \\
\hline 6. & & $\mathrm{x}_{5}$ & $\begin{array}{l}-10.6342^{\mathrm{NS}} \\
(7.810345)\end{array}$ & $-1.36155^{\mathrm{NS}}$ & \\
\hline 7. & & $\mathrm{x}_{6}$ & $\begin{array}{l}16.18642^{* * * *} \\
(2.428331)\end{array}$ & $6.665657^{* * * ;}$ & \\
\hline 8. & & $\mathrm{x}_{7}$ & $\begin{array}{c}45.66887^{* * * *} \\
(37.39815)\end{array}$ & $1.221153^{* * * *}$ & \\
\hline 9. & & $\mathrm{x}_{8}$ & $\begin{array}{l}4.768853^{*} \\
(3.139343)\end{array}$ & $1.519061^{*}$ & \\
\hline (iv) & \multicolumn{5}{|c|}{ Overall farm size group } \\
\hline 1. & \multirow{8}{*}{60} & $\mathrm{a}$ & $\begin{array}{c}716.0078^{* * *} \\
(947.6455)\end{array}$ & $3.246245^{* * *}$ & \multirow{8}{*}{$\begin{array}{l}0.947637^{* *} \\
(1787.897)\end{array}$} \\
\hline 2. & & $\mathrm{x}_{1}$ & $\begin{array}{l}0.245545^{*} \\
(0.07564)\end{array}$ & $0.755565^{*}$ & \\
\hline 3. & & $\mathrm{x}_{2}$ & $\begin{array}{c}1.398507^{*} \\
(1.995703)\end{array}$ & $0.700759^{*}$ & \\
\hline 4. & & $\mathrm{x}_{3}$ & $\begin{array}{l}-1.89379^{\mathrm{NS}} \\
(4.724446)\end{array}$ & $-0.40085^{\mathrm{NS}}$ & \\
\hline 5. & & $\mathrm{x}_{4}$ & $\begin{array}{l}-29.5739^{\mathrm{NS}} \\
(39.16007)\end{array}$ & $-0.75521^{\mathrm{NS}}$ & \\
\hline 6. & & $\mathrm{x}_{5}$ & $\begin{array}{c}9.466241^{* * * * *} \\
(4.491117)\end{array}$ & $2.10777^{* * *}$ & \\
\hline 7. & & $\mathrm{x}_{6}$ & $\begin{array}{c}2.708045^{*} \\
(1.695795)\end{array}$ & $1.596917^{*}$ & \\
\hline 8. & & $\mathrm{x}_{7}$ & $\begin{array}{l}10.34837^{* * *} \\
(15.08908)\end{array}$ & $0.685819^{* *}$ & \\
\hline 9. & & $\mathrm{x}_{8}$ & $\begin{array}{c}-0.38046^{\mathrm{NS}} \\
(1.41825)\end{array}$ & $-0.26826^{\mathrm{NS}}$ & \\
\hline
\end{tabular}


Table. 2 Result of marginal value product analysis of beneficiaries farm size groups

\begin{tabular}{|c|c|c|c|c|c|}
\hline SN & Variables & Geometric Mean & MVP & MFC & Efficiency \\
\hline (i). & \multicolumn{5}{|l|}{ Marginal farm } \\
\hline 1. & $\mathrm{x}_{1}$ & 7712.69 & 4.21915 & 98 & 0.04305 \\
\hline 2. & $x_{2}$ & 239.363 & 932.569 & 23 & 40.5465 \\
\hline 3. & $\mathrm{x}_{3}$ & 49.4956 & -420.76 & 22 & -19.126 \\
\hline 4. & $\mathrm{x}_{4}$ & 118.756 & $7 \mathrm{E}+17$ & 17 & $4.1 \mathrm{E}+16$ \\
\hline 5. & $\mathrm{x}_{5}$ & 406.416 & -11576 & 200 & -57.881 \\
\hline 6. & $\mathrm{x}_{6}$ & 260.841 & 244.003 & 4 & 61.0008 \\
\hline 7. & $\mathrm{x}_{7}$ & 282.096 & 49745.2 & 175 & 284.258 \\
\hline 8. & $\mathrm{x}_{8}$ & 760.037 & $-7 \mathrm{E}+15$ & 1 & $-7 \mathrm{E}+15$ \\
\hline 9. & $\mathrm{y}$ & 6635.75 & -450560 & 24 & -18773 \\
\hline (ii). & \multicolumn{5}{|l|}{ Small farm } \\
\hline 1. & $\mathrm{x}_{1}$ & 10404.1 & 44.8628 & 98 & 0.45778 \\
\hline 2. & $\mathrm{x}_{2}$ & 1146.43 & 181.774 & 23 & 7.9032 \\
\hline 3. & $\mathrm{x}_{3}$ & 48.933 & -182.76 & 22 & -8.3072 \\
\hline 4. & $\mathrm{x}_{4}$ & 305.331 & 1594.58 & 17 & 93.7986 \\
\hline 5. & $\mathrm{x}_{5}$ & 1188.44 & -4184.5 & 200 & -20.922 \\
\hline 6. & $\mathrm{x}_{6}$ & 929.477 & -8.1187 & 4 & -2.0297 \\
\hline 7. & $\mathrm{x}_{7}$ & 725.483 & 1846.51 & 175 & 10.5515 \\
\hline 8. & $\mathrm{x}_{8}$ & 795.914 & -0.3868 & 1 & -0.3868 \\
\hline 9. & $\mathrm{y}$ & 16865.6 & 102143 & 24 & 4255.95 \\
\hline (iii). & \multicolumn{5}{|l|}{ Medium farm } \\
\hline 1. & $\mathrm{x}_{1}$ & 14158.1 & 16.1802 & 98 & 0.1651 \\
\hline 2. & $x_{2}$ & 1956.09 & 199.5 & 23 & 8.67391 \\
\hline 3. & $\mathrm{x}_{3}$ & 57.1146 & 727.599 & 22 & 33.0727 \\
\hline 4. & $x_{4}$ & 516.804 & -2339.4 & 17 & -137.61 \\
\hline 5. & $\mathrm{x}_{5}$ & 1953.82 & -3004.2 & 200 & -15.021 \\
\hline 6. & $\mathrm{x}_{6}$ & 1713.19 & 91.4533 & 4 & 22.8633 \\
\hline 7. & $\mathrm{x}_{7}$ & 1248.93 & 9547.08 & 175 & 54.5547 \\
\hline 8. & $\mathrm{x}_{8}$ & 1289 & 6.736 & 1 & 6.736 \\
\hline 9. & $\mathrm{y}$ & 28374.6 & -162457 & 24 & -6769 \\
\hline (iv). & \multicolumn{5}{|l|}{ Overall farm } \\
\hline 1. & $\mathrm{x}_{1}$ & 10419.3 & 45.7941 & 98 & 0.46729 \\
\hline 2. & $\mathrm{x}_{2}$ & 965.251 & 43.4703 & 10 & 4.34703 \\
\hline 3. & $x_{3}$ & 50.306 & -58.865 & 22 & -2.6757 \\
\hline 4. & $\mathrm{x}_{4}$ & 284.781 & -735.4 & 17 & -43.259 \\
\hline 5. & $\mathrm{x}_{5}$ & 1079.68 & 2942.42 & 200 & 14.7121 \\
\hline 6. & $\mathrm{x}_{6}$ & 832.766 & 16.835 & 4 & 4.20875 \\
\hline 7. & $\mathrm{x}_{7}$ & 678.538 & 2380.3 & 175 & 13.6017 \\
\hline 8. & $\mathrm{x}_{8}$ & 855.905 & -0.5913 & 1 & -0.5913 \\
\hline 9. & $\mathrm{y}$ & 15744.8 & 22255.9 & 24 & 927.33 \\
\hline
\end{tabular}

(Figures in parenthesis indicates the Standard Error of regression Co-efficient) (*** Significant at 1 per cent, ** significant at 5 per cent and $*$ significant at 10 per cent level) 
Even the positive with significant regression coefficient of a (constant) in overall and nonbeneficiaries farm size groups, shows that their contribution have positive role towards the gross return.

Table 2 reveals that the evaluate how efficiently the farmers of the study area have been utilizing their resources, the marginal value product (MVP) of an input was compared with its respective factor cost. An optimal use of that factor was indicated as the ratio approach unity. The value of ratio greater than unity meant that returns could be increased by using more of that resource and for value of ratio will be less than unity indicates improper use of the resources. The marginal value products of a particular resource indicate the expected addition of that resource to the gross return caused by an addition of one unit of that resource, while other inputs are held constant. The marginal value products of these factors were computed by multiplying the regression coefficient of that resource with the geometric mean of gross return to the geometric mean of each resource. Similar studies were carried out by the Sharma (2002); Sharma (2006); Sharma et al., (2008).

The value of MVP for $\mathrm{x}_{1}$ was having less contribution, which indicates that addition of one unit of this input would be adding Rs. 1926.51 towards the gross return, so it may be continue in future. The value of MVP for $\mathrm{x}_{2}$ was found to be positive in large farm size group, which indicate that addition of one unit of $\mathrm{x}_{2}$ would increase the gross return by Rs. 24.53, so it may be continue in the coming days. The MVP of $\mathrm{x}_{3}$ was found to be positive in small, medium, overall and nonbeneficiaries farm size group, which indicates that addition of one unit of these inputs, would contribute Rs. 94.34, Rs. 309.61, Rs. 61.16 and Rs. 2952.46 on different farm size group, respectively towards the gross income, due to the better prospects by the input for gaining profit after shifting the input variables.

The MVP of $\mathrm{x}_{4}$ in small, medium, large and overall farm size groups were found to be positive values, indicating that addition of one unit of these inputs will increase gross return by Rs. 40.57, Rs. 194.64, Rs. 128.25 and Rs. 643.54, clearly shows that farmers may continue to invest more on these inputs for getting better prospects in the future for more gross income on their farms, whereas additional investment of one unit to these inputs would be increasing the gross returns and further contributing their share towards the gross return.

The MVP of $\mathrm{x}_{5}$ in medium, large and overall farm size groups were found to be positive values, indicating that addition of one unit of these inputs will increase gross return by Rs. 441.51, Rs. 416.47 and Rs. 295.00, which will help the farmers to continue the investment on these inputs for getting more gross income on their farms, whereas additional investment of one unit to these inputs would be decreasing the gross returns and further non-contributing their share to the gross return on a farm.

The MVP of $\mathrm{x}_{6}$ in small farm size group was found to be positive response, indicating that addition of one unit of this input will increase gross return by Rs. 1061.58, which is clear that farmers may continue to invest more on this very input for getting better prospects in the future towards the gross income, which alarm to stop the investment otherwise it may lead to the farmers towards more loss, whereas additional investment of one unit to this input would be increasing the gross returns and further contributing their share towards the gross return too. The MVP of $\mathrm{x}_{7}$ in small and overall farm size groups were found to be positive values, indicating that addition of one unit of these inputs will 
increase gross return by Rs. 129.34 and Rs. 6.78 , clearly shows that farmers may continue to invest more on these inputs for getting better prospects in the future for more gross income, whereas additional investment of one unit to these inputs would be increasing the gross returns and further contributing their share towards the gross return.

The MVP of $\mathrm{x}_{8}$ in small and overall farm size groups were found to be positive values, indicating that addition of one unit of these inputs will increase gross return by Rs. 129.34 and Rs. 6.78, clearly shows that farmers may continue to invest more on these inputs for getting better prospects in the future for more gross income, whereas additional investment of one unit to these inputs would be increasing the gross returns and further contributing their share towards the gross return.

The gross sectional data of overall farm size have been aggregated and the ratio of MVP to its factor cost was computed. It was observed that ratio of $\mathrm{x}_{1}$ to $\mathrm{x}_{8}$ were found to be positive and negative both values. Positive indicates the greater than unity and indicates that the farmers can incurred more investment on those inputs for getting better returns, while the negative values indicating either excess use of inputs and adverse response towards the gross return, which needs to be curtailed immediately and further investment of such inputs must be shifted towards the higher results inputs which will provide the positive contribution to the gross return.

The above result showed that none of the resources were used with optimum efficiency since MVP to factor cost ratio were not equal to unity. It further need shift of input variables for getting better prospects from the same investment of inputs, respectively. Similar studies were carried out by Sharma and Sharma (2018) Tangjang and Sharma (2018).

\section{References}

Analogous. 2016. Agricultural Situation in India. Directorate of Economics and Statistics. Ministry of Agriculture, New Delhi.

Analogous. 2017. Statistical Hand of Nagaland Published by Directorate of Economics and Statistics (various issues), Kohima, Nagaland.

Chishi, S. Kanitoli. and Sharma, Amod. 2018. A Sustainable Impact Assessment Approach of Integrated Watershed Development Programme in Nagaland. International Journal of Current Microbiology and Applied Sciences. 7(11). November: 1661-1668.

Dhakre, D. S. and Sharma, Amod. 2010. Trends of Area, Production and Productivity of Rape-Mustard in Nagaland. Environment and Ecology. 28(1 A): 270-272.

Jamir, Imsunaro. and Sharma, Amod. 2018. Impact Assessment of Adopter and Non-Adopter for Krishi Vigyan Kendra's Training Programmes in the Selected districts of Nagaland. International Journal of Current Microbiology and Applied Sciences. 7(11). November: 2283-2289.

Sharma, A. 2002. Source and Knowledge on beneficiaries about the purpose of credit - A case study of Agra Region of Uttar Pradesh. Journal of Interacademica. 6(3). July: 374-379.

Sharma, A. 2006. Fish Production in Nagaland - A regression approach. Journal of Dairying, Foods and Home Science. March. 25(1). March: 43-46.

Sharma, Amod. 2012a. Inter-state Disparities in Socio-economic Development in North East Region of India. Journal of Agricultural Science. 4(9). September: 236-243.

Sharma, Amod. 2012b. Trends of Area, Production and Productivity of Fruit 
Crops in Nagaland State of North Eastern Hill Region of India. Economic Affairs. 57(3). September: 259-276.

Sharma, Amod. 2013. Trends in Area, Production and Productivity of Food Grain Crops: an Overview. Economic Affairs. 58(1). January: 57-68.

Sharma, Amod. 2014. Sustainable economic analysis and extent of satisfaction level of King Chilli growers in Nagaland. Agriculture for Sustainable Development. 2(1). June: 188-191.

Sharma, Amod. and Kalita, D. C. 2008. Trends of Area, Production and Productivity of Major Fruit Crops in Jammu and Kashmir. Agricultural Situation in India. LXV(7). October: 477-482.

Sharma, Amod. Dhakre, D. S. and Sharma, Rajat. 2008. Inter-District Disparities in Socio-Economic Development in Nagaland. Productivity. 49(2-3): JulyDecember: 196-200.

Sharma, Amod. Tyagi, D. B. Lal, R. C. Nakhro, R and Singh, J. 2007. Resource Productivity of Wheat Cultivation of
Small Farms Under Rainfed Condition A Case Study of Agra District. The Andhra Agricultural Journal 54(3 and 4): 196-198.

Shuya, Keviu. and Sharma, Amod. 2014. Impact and constraints faced by the borrowers of cooperative bank finance in Nagaland. Economic Affairs. 59(4). October: 561-567.

Shuya, Keviu. and Sharma, Amod. 2018. Problems faced by the Borrowers in Utilization and Acquiring of Cooperative Bank Loans in Nagaland. IJED. 14(2). April-June: 52-56.

Walling, Imti. and Sharma, Amod. 2015. Impact of SGRY on beneficiaries and non-beneficiaries in Dimapur district of Nagaland. TJRAR. 15(2). August: 9094.

Walling, Imti.; Sharma, Amod.; Yadav, Mukesh. Kumar.; Rajbhar, Arun, Kumar. and Kalai, Kankabati. 2017. Impact of Agricultural Technology Management Agency on Rural Economy of Nagaland, India. Plant Archiver. 17(2). October: 1511-1516.

\section{How to cite this article:}

Kanitoli Chishi, S. and Amod Sharma. 2019. Resource Use Efficiency on Different Farm Size Groups of Integrated Watershed Development Programmes Beneficiaries in Nagaland. Int.J.Curr.Microbiol.App.Sci. 8(06): 2135-2144. doi: https://doi.org/10.20546/ijcmas.2019.806.253 